\title{
Evidence for continental weathering and riverine input during the Sturtian Glaciation
}

\author{
HAYLEY L BRICKER ${ }^{1}$, IAN FOSTER ${ }^{1,2}$, PERRIN \\ HAGGE $^{3}$, ARNAUD AGRANIER ${ }^{2}$, PIERRE SANSJOFRE ${ }^{4}$, \\ STEFAN V. LALONDE ${ }^{5}$ AND ARADHNA TRIPATI ${ }^{1,2}$
}

${ }^{1}$ University of California, Los Angeles

${ }^{2}$ University Brest

${ }^{3}$ Princeton University

${ }^{4}$ Sorbonne Universite

${ }^{5}$ CNRS-UMR6538 Laboratoire Géosciences Océan

Presenting Author: hbricker@g.ucla.edu

One of the most enigmatic hypotheses about Earth's climate history poses global "snowball" conditions that stimulated the diversification of eukaryotes. The longest hypothesized "snowball" interval in the geologic record occurred during the Cryogenian, with the Sturtian glaciation lasting almost 60 million years ( 720-660 million years ago; Ma). Although the initial "hard snowball" model suggests that a combination of changes in $\mathrm{CO}_{2}$ and albedo could have led to ice-covered oceans and glaciated land masses in the tropics, sedimentary structures suggest there were open ocean and 'slushball' conditions during the Sturtian. Both end-member models have been supported by energy balance calculations and more complex climate models. Here we report hafnium and neodymium isotope data from this interval to test these two sets of interpretations. Data from the Braemar Banded Iron Formation in Australia are similar to modern values for glacial and non-glacial rivers and lakes in Greenland. Results are consistent with periods of glacial retreat and the weathering of exposed continental surfaces prior to the deposition of the global cap carbonates at the end of the Sturtian. These findings support less extreme icehouse conditions during the Cryogenian and are consistent with the 'slushball' model, where regions of the land surface, as well as the mixed layer of the marine environment may have served as habitable oases where light penetration and nutrient delivery was possible. 